\title{
Reduced immune-regulatory molecule expression on human colonic memory CD4 T cells in older adults
}

\author{
Stephanie M. Dillon ${ }^{1}$, Tezha A. Thompson ${ }^{1}$, Allison J. Christians ${ }^{1}$, Martin D. McCarter ${ }^{2}$ and Cara C. Wilson ${ }^{\text {* }}$
}

\begin{abstract}
Background: The etiology of the low-level chronic inflammatory state associated with aging is likely multifactorial, but a number of animal and human studies have implicated a functional decline of the gastrointestinal immune system as a potential driver. Gut tissue-resident memory T cells play critical roles in mediating protective immunity and in maintaining gut homeostasis, yet few studies have investigated the effect of aging on human gut T cell immunity. To determine if aging impacted CD4 T cell immunity in the human large intestine, we utilized multicolor flow cytometry to measure colonic lamina propria (LP) CD4 T cell frequencies and immune-modulatory marker expression in younger (mean \pm SEM: $38 \pm 1.5 \mathrm{yrs}$ ) and older ( $77 \pm 1.6 \mathrm{yrs}$ ) adults. To determine cellular specificity, we evaluated colon LP CD8 T cell frequency and phenotype in the same donors. To probe tissue specificity, we evaluated the same panel of markers in peripheral blood (PB) CD4 T cells in a separate cohort of similarly aged persons.

Results: Frequencies of colonic CD4 T cells as a fraction of total LP mononuclear cells were higher in older persons whereas absolute numbers of colonic LP CD4 T cells per gram of tissue were similar in both age groups. LP CD4 T cells from older versus younger persons exhibited reduced CTLA-4, PD-1 and Ki67 expression. Levels of BCl-2, CD57, CD25 and percentages of activated CD38 ${ }^{+} H L A-D R^{+}$CD4 T cells were similar in both age groups. In memory PB CD4 T cells, older age was only associated with increased CD57 expression. Significant age effects for LP CD8 T cells were only observed for CTLA-4 expression, with lower levels of expression observed on cells from older adults.

Conclusions: Greater age was associated with reduced expression of the co-inhibitory receptors CTLA-4 and PD-1 on LP CD4 T cells. Colonic LP CD8 T cells from older persons also displayed reduced CTLA-4 expression. These ageassociated profiles were not observed in older PB memory CD4 T cells. The decline in co-inhibitory receptor expression on colonic LP T cells may contribute to local and systemic inflammation via a reduced ability to limit ongoing $T$ cell responses to enteric microbial challenge.
\end{abstract}

Keywords: Aging, Human, Gut, Tissue resident memory T cells, CD4 T cells, CD8 T cells

\footnotetext{
* Correspondence: cara.wilson@cuanschutz.edu

'Department of Medicine, University of Colorado Anschutz Medical Campus, Aurora, Colorado 80045, USA

Full list of author information is available at the end of the article
}

(c) The Author(s). 2021 Open Access This article is licensed under a Creative Commons Attribution 4.0 International License, which permits use, sharing, adaptation, distribution and reproduction in any medium or format, as long as you give appropriate credit to the original author(s) and the source, provide a link to the Creative Commons licence, and indicate if changes were made. The images or other third party material in this article are included in the article's Creative Commons licence, unless indicated otherwise in a credit line to the material. If material is not included in the article's Creative Commons licence and your intended use is not permitted by statutory regulation or exceeds the permitted use, you will need to obtain permission directly from the copyright holder. To view a copy of this licence, visit http://creativecommons.org/licenses/by/4.0/ The Creative Commons Public Domain Dedication waiver (http://creativecommons.org/publicdomain/zero/1.0/) applies to the data made available in this article, unless otherwise stated in a credit line to the data. 


\section{Background}

Aging is associated with a chronic inflammatory state ("inflammaging") which is linked to geriatric comorbidities, including cardiovascular disease, impaired mobility, cognitive decline and all-cause mortality $[1,2]$. The etiology of inflammaging is likely multifactorial, but a number of animal studies have implicated a functional decline of the gastrointestinal (GI) tract as a potential driver. For example, studies in the Drosophila model have linked age-associated loss of intestinal barrier function to alterations in intestinal microbiota (dysbiosis), systemic metabolic defects, inflammation and agerelated mortality [3, 4]. Age-associated links between enteric microbiota and local and systemic inflammation were also demonstrated in murine models [5, 6]. Older non-human primates had greater systemic inflammation, higher levels of biomarkers indicative of microbial translocation and intestinal barrier dysfunction, observations supported by increased gut permeability to large molecules [7-9]. Our previous study suggested that disruption of gut homeostasis and its link to systemic inflammation also occurs as part of human aging whereby plasma biomarkers of epithelial barrier damage and microbial translocation increased with age similar to other indicators of inflammaging (IL-6, C-reactive protein [CRP]) in persons aged 20-100 years [10]. However, few studies have investigated how aging directly impacts human intestinal immunity.

Gut $\mathrm{T}$ cells play critical roles in mediating both protective immunity and in maintaining gut homeostasis and epithelial barrier function (reviewed in [11]). It is therefore conceivable that alterations in the gut $\mathrm{T}$ cell landscape as we age could impact gut immunity against enteric pathogens as well as intestinal barrier function. Gut CD4 T cell development and their ability to induce tolerance is finely tuned by interactions between the host $\mathrm{T}$ cells and the local microbial community [12], yet a number of studies have associated aging with alterations in the structure of these enteric microbial communities [13] which may therefore further modulate local $\mathrm{T}$ cell immunity. Human gut $\mathrm{T}$ cells are primarily tissue-resident memory cells with distinct transcriptomic, phenotypic and functional properties compared to their blood counterparts [14-16] preventing generalization of our understanding of age effects on blood $\mathrm{T}$ cells to those in the gut. Indeed, the composition of naive and memory CD4 and CD8 T cell subsets in human small and large intestine remained relatively unchanged with age; contrasting with decreases in naïve $\mathrm{T}$ cells and increases in effector memory subsets in peripheral blood (PB) and other lymphoid and mucosal sites $[16,17]$.

In a recent study investigating the impact of age on human small intestine $\mathrm{T}$ cells, we demonstrated that jejunum lamina propria (LP) CD4 T cells from older persons ( $\geq 65 \mathrm{yrs}$ ) displayed phenotypic and functional differences versus those from younger persons ( $\leq 45 \mathrm{yrs}$ ) including reduced expression of the co-inhibitory molecule CTLA-4, increased spontaneous cell death and reduced frequencies of $\mathrm{T}$ helper 17 cells [18]. Utilizing in situ imaging, Senda et al. found an age-dependent decrease in naïve CD4 and CD8 T cell frequencies located in isolated lymphoid follicles (ILFs) within jejunum tissue, but frequencies in colonic ILFs were unchanged [19] signifying that age effects may differ throughout the intestinal tract. In fact, the GI tract is known for its regional specialization with distinctive differences in anatomical structure, distribution of innate and adaptive immune cells and in the local composition of the various microbial species $[20,21]$. Therefore, to expand on our previous work investigating small intestinal $\mathrm{T}$ cells, we undertook this exploratory study to evaluate the impact of age on the frequency and immune phenotype of human colon LP CD4 T cells obtained from younger persons aged $\leq 45$ yrs and older persons aged $\geq 65$ yrs. To determine whether aging-related findings were gut $\mathrm{T}$ cell subset-specific, we also evaluated the frequency and phenotypic profiles of human LP CD8 T cells. Finally, given that gut $\mathrm{T}$ cells are primarily tissue-resident memory cells, we also probed the potential tissue specificity of the age-associated phenotype by investigating the same profiles in memory PB CD4 $\mathrm{T}$ cells in a separate cohort of similarly aged younger and older persons.

\section{Results}

\section{Colonic LP CD4 T cells from older persons exhibit} reduced CTLA-4, PD-1 and Ki67 expression

Multicolor flow cytometry was used to evaluate baseline frequencies and immune phenotypic profiles of LP CD4 $\mathrm{T}$ cells from younger $(\leq 45 \mathrm{yrs})$ and older donors $(\geq 65$ yrs) (Additional file 1: Figure S1). Frequencies of total LP CD4 T cells, as a fraction of total viable, CD $45^{+}$ LPMC, were significantly higher in older samples compared with younger samples (Fig. 1a). However, the absolute number of LP CD4 T cells normalized to gram of tissue, was similar between younger and older samples (Fig. 1a).

To determine the effect of age on LP CD4 T cell phenotype, canonical indicators of $\mathrm{T}$ cell survival (antiapoptotic/pro-survival Bcl-2), proliferation (Ki67), senescence (CD57), activation (CD25 [IL-2R $\alpha$ ]; CD38 and HLA-DR co-expression) and negative regulation (CTLA4, PD-1, Tim-3, Lag-3) were measured ex vivo (baseline) and compared between younger and older samples. On average, most LP CD4 T cells from both younger (mean \pm SEM: $99.72 \pm 0.07 \%$ ) and older (99.68 $\pm 0.07 \%$ ) samples expressed Bcl-2 (Additional File 1: Fig. S1b). Levels of Bcl-2 expression, measured as geometric mean fluorescence intensity (GMFI), were higher in older (11, $108 \pm 779$ GMFI) compared to younger samples (9147 \pm 
A

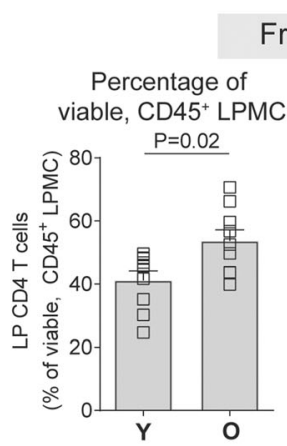

Frequencies

Absolute number

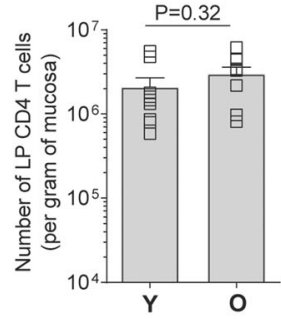

B

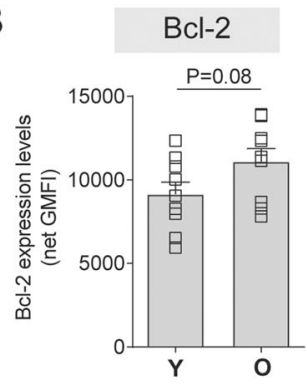

C
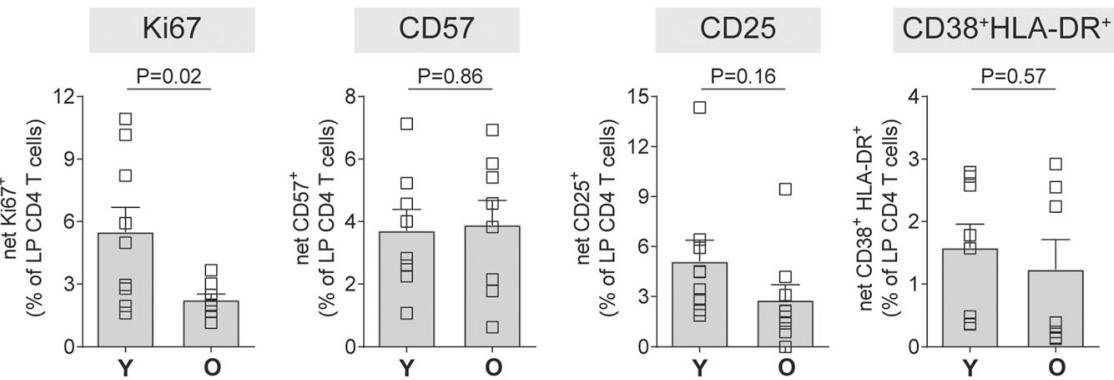

D

CTLA-4
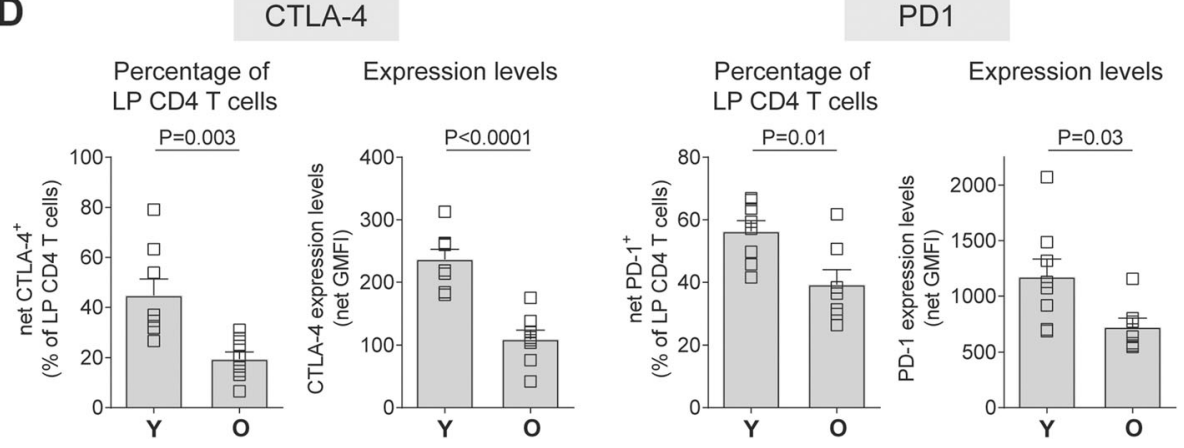

PD1

Fig. 1 Age is associated with alterations in phenotypic profiles of human LP CD4 T cells. LPMC were isolated from colonic tissue samples obtained from younger ( $Y ; \leq 45 \mathrm{yrs}$ ) and older $(\mathrm{O} ; \geq 65 \mathrm{yrs})$ persons ( $N=9 /$ age group unless otherwise stated) and multi-color flow cytometry used to evaluate $\mathbf{a}$ baseline frequencies and baseline expression of $\mathbf{b} \mathrm{BCl}-2, \mathbf{c} C \mathrm{CD} 38$ and HLA-DR (Y N=8; O N=7), CD25, Ki67 (O N =8), CD57 (Y N =8; $\mathrm{O} N=7)$ or $\mathbf{d} C T L A-4(Y N=8 ; O N=8)$ and PD-1 ( $Y N=8 ; O N=7)$. Frequency values are shown as a percentage of $L P$ CD4 T cells in viable, CD45 $5^{+}$LPMC or as absolute number per gram and phenotypic expression as the percentage of LP CD4 T cells expressing each marker or as total expression levels on LP CD4 T cells (Geometric Mean Fluorescence Intensity; GMFI). Isotype control (BCl-2, CD38, Ki67, CTLA-4), Fluorescence minus one (FMO; CD25) or FM4 (HLA-DR, CD57, PD-1) values have been removed (net). Bar graphs represent mean \pm SEM with individual samples shown as open squares. Statistical analysis: unpaired t-tests

727 GMFI), but this did not reach statistical significance $(P=0.08)$ (Fig. 1b). In younger samples, Ki67 was expressed by $5.5 \% \pm 1.2 \%$ of total LP CD 4 T cells and significantly fewer LP CD4 $\mathrm{T}$ cells expressed this proliferation marker in older samples $(2.2 \pm 0.3 \%)$ (Fig. 1c). Percentages of LP CD4 T cells expressing CD57, CD25 or co-expressing CD38 and HLA-DR $\left(\mathrm{CD} 38^{+}\right.$HLA-DR $\left.^{+}\right)$ were not statistically different between younger and older samples (Fig. 1c).

The percent of LP CD4 T cells expressing CTLA-4 was significantly lower in older samples $(19.4 \pm 2.9 \%)$ compared to younger samples $(44.8 \pm 6.6 \% ; P=0.003)$ (Fig. 1d). Overall expression levels of CTLA-4 were also significantly lower in older samples (O: $110 \pm 14$ GMFI; Y: $237 \pm 16$ GMFI; $P<0.0001$ ) (Fig. 1d). Both the percentage of older LP CD4 T cells expressing PD-1 (39.3 \pm $4.8 \%)$ and overall expression levels (722 \pm 82 GMFI) were significantly lower than on younger LP CD4 T cells $(56.3 \pm 3.4 \%, \quad P=0.01 ; \quad 1173 \pm 161 \quad$ GMFI,$\quad P=0.03)$ (Fig. 1d). On average, $<0.5 \%$ of LP CD4 T cells expressed Tim-3 in both younger $(0.4 \pm 0.1 \%)$ and older $(0.3 \pm 0.1 \%)$ samples with no age-effect observed $(P=$ 0.65) (data not shown). Similarly, Lag-3 was expressed by few LP CD4 T cells in younger $(0.8 \pm 0.2 \%)$ and older $(0.5 \pm 0.2 \%)$ samples with no statistical difference observed $(P=0.22)$ (data not shown). 


\section{PB memory CD4 T cells from older persons display increased CD57 expression}

We next evaluated expression of the same panel of makers in PB CD4 $\mathrm{T}$ cells from a separate cohort of younger ( $\leq 45 \mathrm{yrs}$ ) and older ( $\geq 65 \mathrm{yrs})$ donors. Given that the majority of LP CD4 T cells $(89.1 \pm 4.2 \%)$ expressed markers indicative of an effector memory cell phenotype (CD45RA ${ }^{-} \mathrm{CD}^{2} \mathrm{~L}^{-}$) (Additional File 2: Figure S2a), the age effects on phenotypic marker expression of PB CD4 $\mathrm{T}$ cells were evaluated in PB CD4 $\mathrm{T}$ cells enriched for memory cells based on lack of CD45RA expression (Additional File 2: Figure S2b). Frequencies of $\mathrm{PB}$ CD45RA $^{-}$CD4 $\mathrm{T}$ cells were not significantly different between younger and older samples evaluated either as the fraction of total memory cells within total CD4 T cells or within total viable PB mononuclear cells (PBMC) (Additional File 2: Figure S2c). In contrast to older LP
CD4 T cells, expression of CTLA-4 and PD-1 were similar between younger and older PB CD45RA- CD4 T cells (Fig. 2a). Age effects were also not observed for $\mathrm{PB}$ $\mathrm{CD}_{45 \mathrm{RA}^{-}}$cells expressing Ki67 or Bcl-2. Similar to LP CD4 T cells, percentages of $\mathrm{CD} 25^{+}$or $\mathrm{CD} 38^{+} \mathrm{HLA}-\mathrm{DR}^{+}$ PB CD45RA ${ }^{-}$CD4 T cells were not significantly different between the age groups. In contrast to LP CD4 T

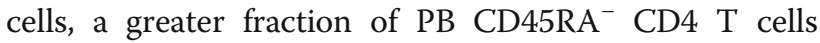
expressed CD57 in older versus younger samples (Fig. 2b).

\section{Colonic CD8 T cells have distinct immune phenotypes compared to colonic CD4 T cells}

To determine if age-effects noted in colon LP CD4 T cells were also reflected in colon CD8 T cells, we next evaluated frequency and phenotype of total CD8 T cells in the same colon samples in which we had analyzed
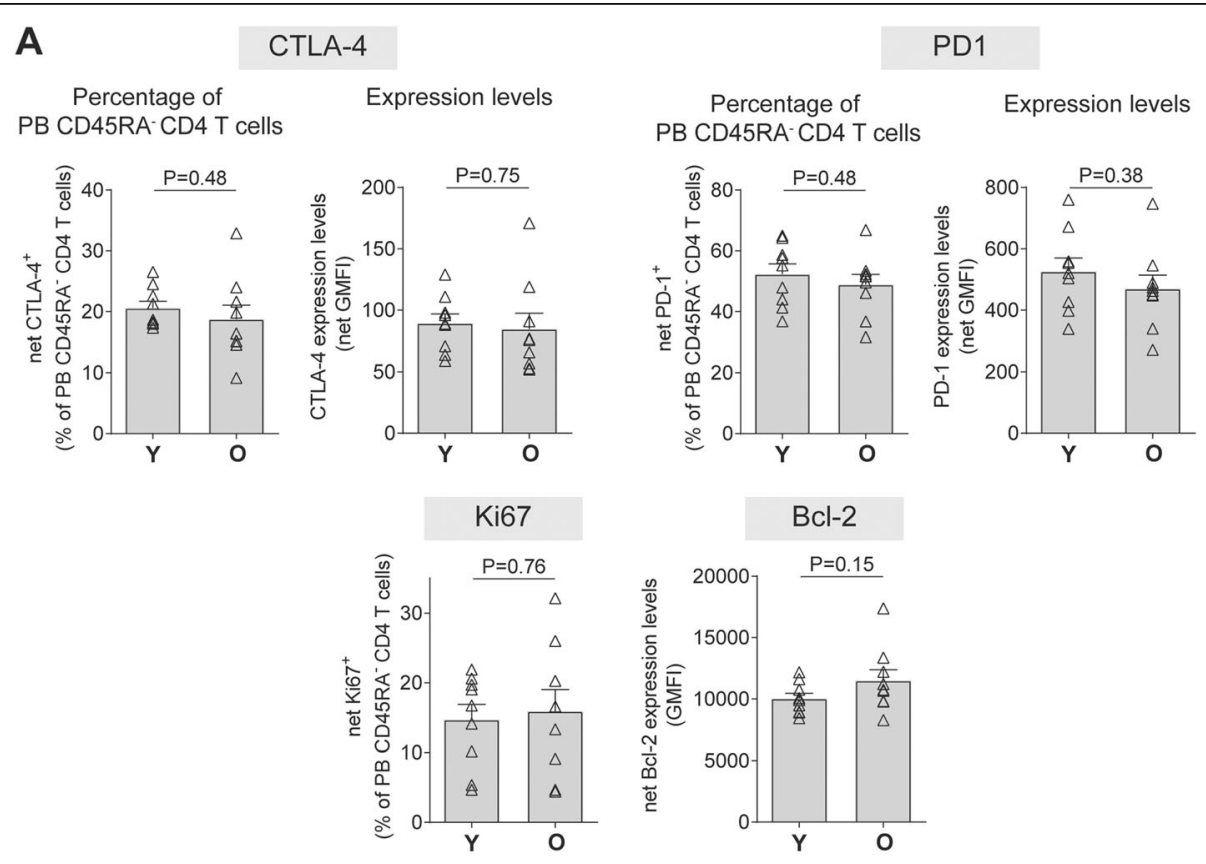

B
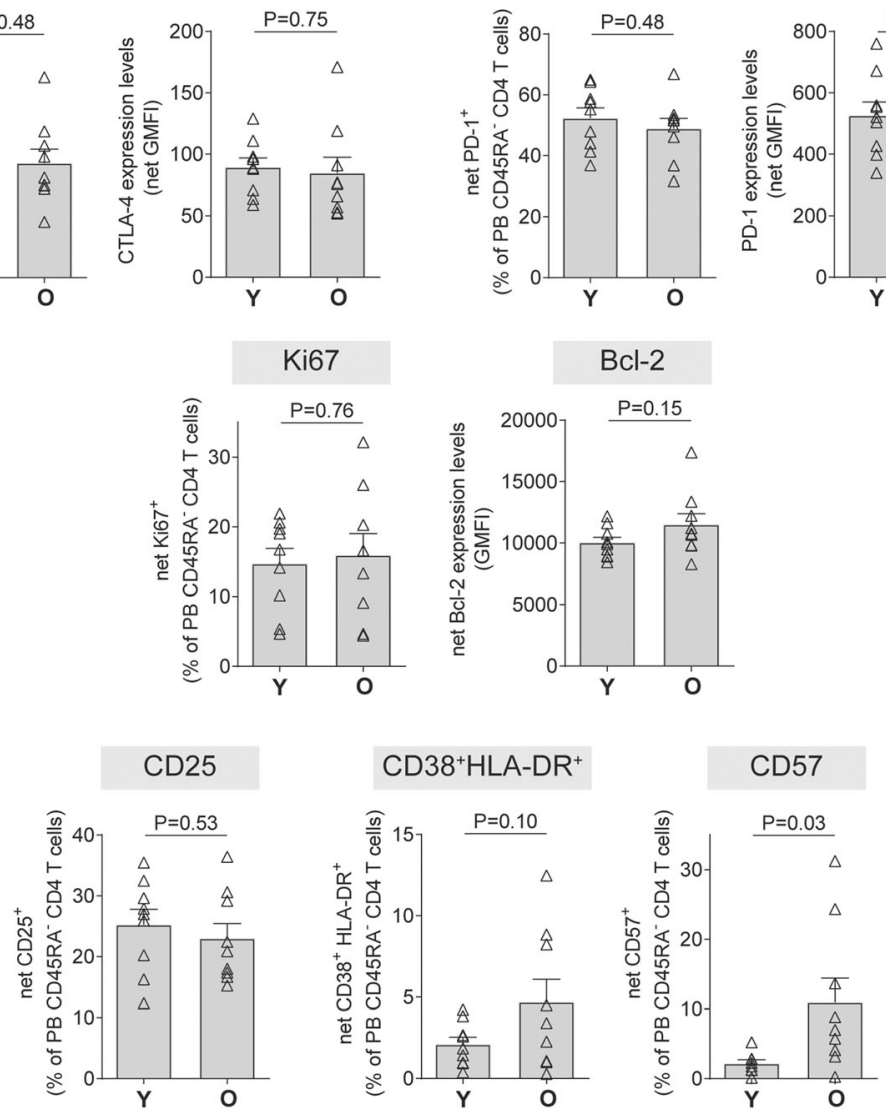

Fig. 2 PB CD45RA- CD4 T cells have limited age-associated alterations in immune phenotype. PBMC were isolated from blood samples obtained from younger ( $Y ; \leq 45 \mathrm{yrs}$ ) and older ( $\mathrm{O} ; \geq 65 \mathrm{yrs}$ ) persons ( $N=9$ /age group unless otherwise stated) and multi-color flow cytometry used to evaluate baseline expression of a CTLA-4, PD-1, Ki67, BCl-2 or b CD25, CD38 and HLA-DR, or CD57 (Y N=8). Values are shown as the percentage of LP CD4 T cells expressing each marker or as total expression levels on LP CD4 T cells (Geometric Mean Fluorescence Intensity; GMFI). Isotype control (BCl-2, CD38, Ki67, CTLA-4), Fluorescence minus one (FMO; CD25) or FM4 (HLA-DR, CD57, PD-1) values have been removed (net). Bar graphs represent mean \pm SEM with individual samples shown as open triangles. Statistical analysis: unpaired t-tests 
CD4 $\mathrm{T}$ cell profiles (Additional File 1: Figure S1a; Additional File 3: Figure S3a). Of note, the majority of LP $\mathrm{CD} 8 \mathrm{~T}$ cells in younger persons were also effector memory $\mathrm{T}$ cells $(65.9 \pm 7.9 \%)$ (Additional File 3: Figure S3b). However, this fraction of memory cells in CD8 T cells was significantly lower than the percentage of effector memory LP CD4 T cells (Additional File 3: Figure S3c). A greater fraction of CD8 $\mathrm{T}$ cells were terminally differentiated effector memory (TDEM; CD45RA ${ }^{+} \mathrm{CD}_{2} \mathrm{~L}^{-}$) cells versus LP CD4 T cells. Further comparisons between younger colon $\mathrm{CD} 8$ and $\mathrm{CD} 4 \mathrm{~T}$ cells highlighted additional differences between these two cell populations despite both residing at the same tissue site (Additional File 4: Table S1). Frequencies of CD8 T cells were significantly lower than $\mathrm{CD} 4 \mathrm{~T}$ cells and, on average, only constituted $14 \%$ of total viable CD $45^{+}$LPMC versus $41 \%$ for CD4 $\mathrm{T}$ cells and $22.3 \%$ of total $\mathrm{LP} \mathrm{CD}^{+} \mathrm{T}$ cells versus $70.1 \%$ for $\mathrm{CD} 4 \mathrm{~T}$ cells. CD8 $\mathrm{T}$ cells had lower expression of Bcl-2 than $\mathrm{CD} 4 \mathrm{~T}$ cells and fewer CD8 $\mathrm{T}$ cells expressed CD25, CTLA-4 and PD-1. Conversely, a greater percentage of LP CD8 $\mathrm{T}$ cells were CD38 ${ }^{+} \mathrm{HLA}$ $\mathrm{DR}^{+}$and expressed CD57.

\section{Colonic CD8 T cells from older persons have lower levels of CTLA-4 but not PD-1}

Frequencies of LP CD8 T cells, either as total number of cells per gram of tissue or fraction of viable LPMC, were not significantly different between younger and older samples (Fig. 3a). Percentages and expression levels of CTLA-4 were significantly lower in LP CD8 T cells from older samples (Fig. 3b), similar to the age effect observed in LP CD4 T cells (Fig. 1). No statistically significant differences in PD-1, Ki67 or Bcl-2 expression by LP CD8 T cells in younger and older samples were noted (Fig. 3c). Although the percentage of LP CD8 T cells coexpressing CD38 and HLA-DR was, on average, lower in samples from older persons $(2.2 \pm 1.0 \%)$ versus younger samples $(5.8 \pm 1.3 \%)$, this difference did not reach statistical significance $(P=0.07)$ (Fig. 3d). Similar to LP CD4 T cells, expression of CD25 and CD57 was not statistically different between younger and older samples.

\section{Discussion}

It is now well accepted that peripheral blood CD4 and CD8 $\mathrm{T}$ cells undergo dynamic changes as humans age, and these changes likely have critical consequences on the ability to mount immune responses against pathogens as well as develop effective vaccine responses (reviewed in [22-24]). However, recent studies have underlined the inherent differences between circulating and tissue-resident $\mathrm{T}$ cells, including those that reside in the gut mucosa $[14,25]$, highlighting that care must be taken in simply extrapolating what we know about age effects on blood $\mathrm{T}$ cells to those in other tissues. To further our understanding of the potential impact of aging on human colon $\mathrm{CD} 4 \mathrm{~T}$ cells, we undertook this exploratory study to measure expression levels of a panel of molecules generally considered as canonical indicators of blood T cell survival, proliferation, senescence, activation and negative regulation directly ex vivo in colon tissue samples obtained from younger and older persons.

Our study demonstrated that in older persons, LP $\mathrm{CD} 4 \mathrm{~T}$ cells displayed features of a dysregulated phenotype primarily characterized by decreased expression of CTLA-4 and PD-1, molecules typically associated with limiting CD4 $\mathrm{T}$ cell activation. We have previously observed lower expression of CTLA-4 on LP CD4 T cells obtained from jejunum samples of a different cohort of older persons [18], suggesting an age effect may occur, at least in the context of CTLA-4 expression, throughout the GI tract. Notably, in this current study, we did not observe differences in expression of CTLA-4 or PD-1 between younger and older memory PB CD4 $\mathrm{T}$ cells (albeit from unmatched donor blood samples), potentially highlighting a gut-specific effect. Although previous studies have noted an age-associated increase in CTLA4 or PD-1 expression on blood CD4 T cells [26-29], the lack of an apparent age effect observed here is in agreement with a number of other studies [30-33] and may relate to study populations (e.g. age range, sex) and/or the type of CD4 T cell evaluated (e.g. total versus memory populations).

CTLA-4 and PD-1 are inhibitory receptors that serve as regulators of $\mathrm{T}$ cell activation. In healthy persons (aged 57-65 yrs), higher percentages of CD4 T cells expressing CTLA- 4 were noted in ileum and rectal biopsies versus $\mathrm{CD} 4 \mathrm{~T}$ cells isolated from $\mathrm{PB}$ [34]. We previously postulated that high expression of these immune-inhibitory receptors in the gut may be an important regulatory mechanism to limit unnecessary CD4 $\mathrm{T}$ cell activation in response to the local enteric commensal microbial community [18]. Certainly, their critical role in controlling gut $\mathrm{T}$ cell immunity is highlighted by recent observations that cancer-based immunotherapies designed to block these molecules can sometimes lead to unintended immune-mediated gut inflammation [35, 36]. A number of studies have linked age-associated systemic inflammation to gut epithelial barrier dysfunction, local inflammation and/or dysbiosis [3-10]. Therefore, it is tempting to speculate that an inability to limit inflammatory colonic CD4 $\mathrm{T}$ cell responses to translocating bacteria due to decreased signaling through CTLA-4 and PD-1 might contribute to an inflammatory gut environment in older persons. However, future studies are needed to determine the functional outcomes of reduced expression of these molecules on colonic LP CD4 T cells as we age. Although both molecules are generally grouped together as 
A

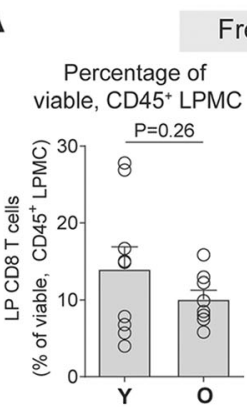

Frequencies

Absolute number

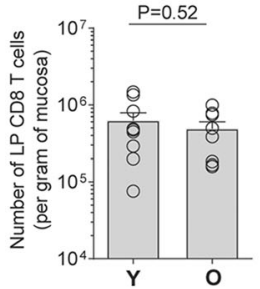

C

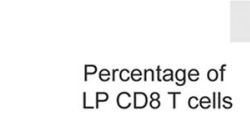

PD1
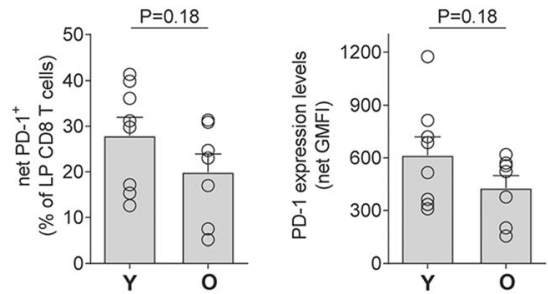

B

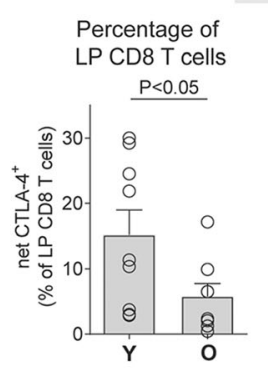

Ki67
CTLA-4

Expression levels

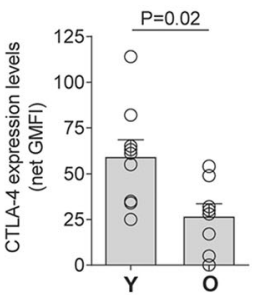

$\mathrm{Bcl}-2$

D
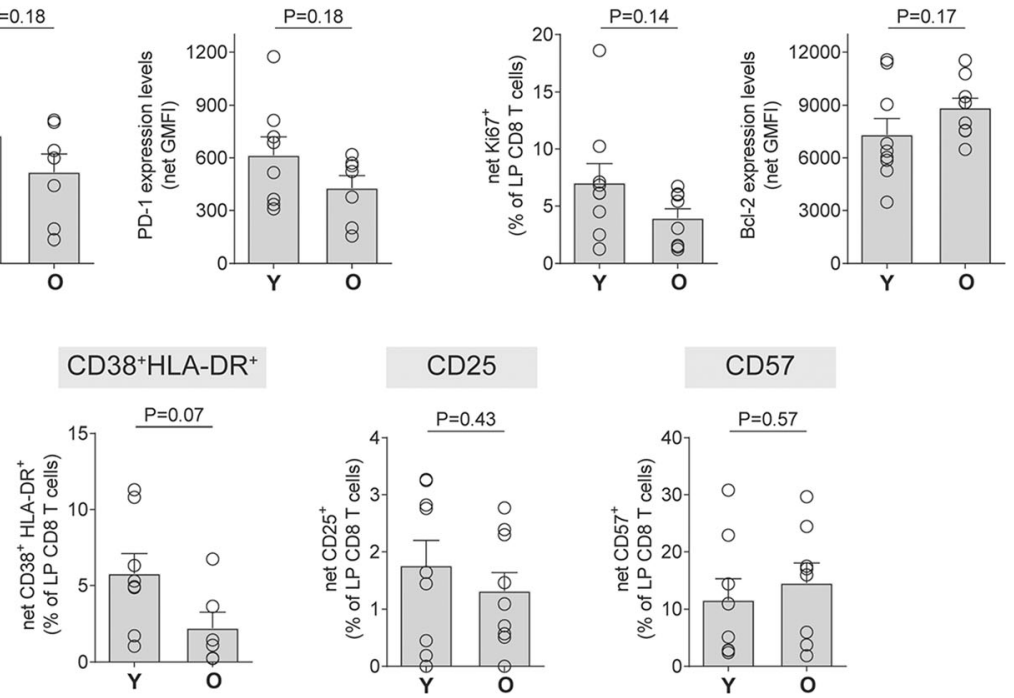

Fig. 3 Age effects on LP CD8 T cells. LPMC were isolated from colonic tissue samples obtained from younger ( $Y$; $\leq 45 \mathrm{yrs})$ and older ( $\mathrm{O} ; \geq 65 \mathrm{yrs})$ persons ( $N=9$ /age group unless otherwise stated) and multi-color flow cytometry used to evaluate a baseline frequencies and baseline expression of $\mathbf{b} C T L A-4(\mathrm{O} N=8), \mathbf{c} P D-1(\mathrm{Y} N=8 ; \mathrm{O} N=8), \mathrm{Ki} 67(\mathrm{O} \mathrm{N}=8), \mathrm{BCl}-2$, and $\mathbf{d}$ CD38 and HLA-DR $(\mathrm{Y} \mathrm{N}=8 ; \mathrm{O} N=6), \mathrm{CD} 25$, and CD57 (Y $\mathrm{N}=8 ; \mathrm{ON}=8$ ). Frequency values are shown as a percentage of $L P C D 4 \mathrm{~T}$ cells in viable, $C D 45^{+} \mathrm{LPMC}$ or as absolute number per gram and phenotypic expression as the percentage of LP CD8 T cells expressing each marker or as total expression levels on LP CD8 T cells (Geometric Mean Fluorescence Intensity; GMFI). Isotype control (BCl-2, CD38, Ki67, CTLA-4), Fluorescence minus one (FMO; CD25) or FM4 (HLA-DR, CD57, PD-1) values have been removed (net). Bar graphs represent mean \pm SEM with individual samples shown as open circles. Statistical analysis: paired t-tests

"inhibitory receptors", how this regulation of $\mathrm{T}$ cell function is achieved differs between the two, both with timing of expression and the ligands that activate their respective signaling pathways $[37,38]$. Thus, the downstream consequences of lower expression of each of these molecules will likely be differentially influenced by age-associated intrinsic and extrinsic factors.

It will also be important to determine what mechanisms drive these altered profiles associated with aging. Human gut $\mathrm{T}$ cells are primarily tissue-resident memory cells, suggesting that these driving factors would likely be a part of the local environment [14-16]. However, gut-associated inflammation has been linked to the homing of PB CD4 T cells into gut tissue, particularly to gut-associated lymphoid tissue [39, 40]. This raises the interesting possibility that the aging-associated profiles may primarily be expressed on recently recruited $\mathrm{PB}$ CD4 T cells. Similar to the functional consequences of reduced regulatory molecule expression, the mechanisms driving reduced regulatory molecule expression will likely be multifactorial.

In addition to reduced expression of co-inhibitory receptors, significantly fewer LP CD4 T cells in older persons expressed Ki67, an indicator of homeostatic proliferation and cell turnover. However, the proportion of Ki67-expressing LP CD4 T cells was generally low in younger donors (average $<5.5 \%$ ). Although this finding suggests that LP CD4 $\mathrm{T}$ cells normally exist in a more 
quiescent state with limited cellular turnover compared to circulating memory CD4 T cells, it is difficult to determine whether the further reduction observed in older samples has biological significance.

A number of recent studies have highlighted that the function of gut CD8 T cells, and their ability to respond to pathogenic and tumor challenge, is also influenced by the enteric commensal microbial community [41, 42]. These studies prompted us to investigate the impact of age on human colonic CD8 T cells. Quantitative and qualitative differences between CD8 and CD4 T cells from donor-matched younger samples were noted. CD8 $\mathrm{T}$ cells constituted a much smaller fraction of total $\mathrm{T}$ cells in colonic LPMC, and a greater fraction expressed canonical makers of activation $\left(\mathrm{CD} 38^{+} \mathrm{HLA}-\mathrm{DR}^{+}\right)$and senescence (CD57). Conversely, levels of the coinhibitory molecules CTLA-4 and PD-1 were significantly lower on CD8 $\mathrm{T}$ cells relative to their CD4 counterparts. These distinct phenotypes may reflect functional differences between the two $\mathrm{T}$ cell populations with gut resident CD8 $\mathrm{T}$ cells primarily being involved in host defense while LP CD4 T cells also have additional roles in homeostasis and may require greater regulation. However, despite the differential expression patterns between the two $\mathrm{T}$ cell populations, the age effects were generally similar with lower expression of CTLA-4, PD-1 and homeostatic turnover (Ki67) although the latter two age effects were more pronounced for older CD4 $\mathrm{T}$ cells. Thus, the factors driving ageassociated gut $\mathrm{T}$ cell dysregulation may be similar for both CD4 and CD8 T cells and both populations may contribute to an inflammatory state in older persons.

This study is exploratory in nature due to having a relatively small sample size in each age group, to having patient mismatched gut and blood samples, and to the lack of detailed clinical information, including other comorbidities and medication use, for the study cohorts. A larger, well-controlled clinical study that includes participant-matched colonic tissue and blood samples and comprehensive clinical information is required to fully confirm our tissue-specific and age-related findings. Furthermore, given the recent observation of an ageassociated decline of PD-1-expressing human PB CD4 T cells in specific memory subsets of older females [29], it will be important to determine if age and sex intersect to differentially impact phenotype and function of LP CD4 and CD8 T cells.

\section{Conclusions}

Although the effects of aging in humans are well established for circulating CD4 and CD8 T cells, the inherent differences between blood and tissue-resident immune cells prevents us from extrapolating this to gut tissueresident memory $\mathrm{T}$ cell populations. We had previously shown that small intestinal CD4 $\mathrm{T}$ cells from older persons displayed a dysregulated phenotype with decreased expression of the co-inhibitory molecule CTLA-4. We now expand on these findings and demonstrate that large intestinal CD4 and CD8 $\mathrm{T}$ cells also display an altered immune phenotype consistent with immune dysregulation with aging. In the GI tract, $\mathrm{T}$ cells are critical for both immunity and maintaining homeostasis, so alterations with age may have significant impacts on gut health. Our study provides the ground work for future investigations into the impact of age on gut $\mathrm{T}$ cell immunity to definitively link changes in $\mathrm{T}$ cell phenotype and function to local inflammation and epithelial barrier breakdown that lead to increased systemic inflammation and age-associated co-morbidities.

\section{Methods}

\section{Collection and isolation of colon LP mononuclear cells (LPMC)}

Human colon tissue samples were obtained through the University of Colorado Anschutz Medical Campus from patients scheduled for elective abdominal surgery. Tissue samples were obtained from surgical anastomotic junctions and were macroscopically healthy and normal in appearance. No samples were obtained from patients with a history of Inflammatory Bowel Disease, HIV-1 infection, treatment with immunosuppressive drugs, or recent chemotherapy (within 8 weeks). All patients voluntarily gave informed consent to permit unrestricted use of the samples for research purposes. Protected patient information for all samples was de-identified to the investigators and only age, sex and reason for surgery were provided (Additional File 5: Table S2) with the majority of samples in both younger and older groups obtained from persons undergoing elective surgery for gastrointestinal-associated cancers. Research associated with the use of LPMC was reviewed by the Colorado Multiple Institutional Review Board (COMIRB) at the University of Colorado Anschutz Medical Campus and deemed Not Human Subject Research as defined by their polices in accordance with OHRP and FDA regulations. For studies investigating frequencies and phenotypic profiles of CD4 and CD8 T cells, a total of 18 colonic samples were obtained with 9 samples obtained from younger persons (mean age: 37 yrs., range 27-44; 5 males, 4 females) and 9 samples obtained from older persons (mean age: 80 yrs., range 72-88; 6 males and 3 females). For measurement of memory CD4 and CD8 T cell populations, samples were obtained from younger donors only $(N=6$; mean 40 yrs., range 32-44; 2 males, 4 females). LPMCs were isolated from the tissue samples in a two-step procedure with removal of the epithelial layer and then disassociation of the LP layer into single cells using Collagenase D (Sigma-Aldrich, St Louis, MO) 
prior to cryopreservation, as previously described [18, $43-47]$.

\section{Collection and isolation of PBMC}

Human PBMC samples were selected from an in house" biorepository of cryopreserved samples obtained from donors identifying as healthy and HIV-1 negative. Donors were recruited from the local research community and through the University of Colorado Hospital (UCH) Internal Medicine Clinic; due to the retrospective nature of this study, these donors were recruited under a consent process that did not include access to medical records and only age and sex were recorded [10]. All the study subjects participated voluntarily and gave written, informed consent for use of the isolated PBMC for research studies. This study was approved by COMIRB. A total of 18 PBMC samples were obtained with 9 samples obtained from younger persons (mean age: 33 yrs., range 27-40; 4 males, 5 females) and 9 samples obtained from older persons (mean age: 79 yrs., range 68-91; 6 males and 3 females). PBMC were isolated using standard Ficoll-Hypaque density gradient centrifugation, cryopreserved and stored in liquid nitrogen as previously detailed [48-50].

\section{Surface and intracellular multi-color flow cytometry staining}

All antibodies and dyes used in the various multi-color flow cytometry staining panels are detailed in Additional File 6: Table S3. LPMCs and PBMCs were stained with viability dye and various combinations of antibodies directed against surface molecules (CD45, CD3, CD4, CD8, CD45RA, CD62L, CD57, CD38, HLA-DR, CD25, PD-1, LAG-3, TIM-3) followed by intracellularly staining for Bcl-2, Ki67 or CTLA-4, using Foxp3/Transcription Factor Staining Buffers (eBioscience, Invitrogen) as previously detailed [18]. Multiple staining panels were used to accommodate the listed fluorochromes. In some instances, low cell yields prevented staining with all panels.

\section{Flow cytometry acquisition and analysis}

All flow cytometry data were collected using the LSRII flow cytometer (BD Biosciences, San Jose, CA) and the BD FACSDiva software ( $\mathrm{v} 9, \mathrm{BD}$ Biosciences). Quality control measures were completed daily as detailed [18]. FlowJo $^{\text {tw }}$ Software for Windows (v10.6.2, Ashland, OR) was used to analyze all flow cytometry data. Flowcytometry gating strategies for LP T cells are detailed in Additional File 1: Figure S1A. $\mathrm{LP} \mathrm{CD}^{+} \mathrm{CD}^{+}$and $\mathrm{CD}^{+}$ $\mathrm{CD}^{+} \mathrm{T}$ cells were identified within $\mathrm{CD} 45^{+}$, viable, single lymphocytes (based on forward and side scatter properties). Control and antibody expression profiles are shown for Bcl-2, Ki67, CD57, CD25, CD38, HLA-DR, CTLA-4 and PD-1 by CD4 T cells in Additional File 1: Figure $\mathrm{S} 1 \mathrm{~B}$, by $\mathrm{CD} 8 \mathrm{~T}$ cells in Additional File 4: Figure S3A) and for identification of memory $\mathrm{T}$ cell subsets as effector memory (CD45RA $\left.{ }^{-} \mathrm{CD} 6 \mathrm{~L}^{-}\right)$, central memory $\left(\mathrm{CD} 45 \mathrm{RA}^{-} \mathrm{CD} 2 \mathrm{~L}^{+}\right)$, terminally-differentiated effector memory $\left(\mathrm{CD} 45 \mathrm{RA}^{+}\right.$and $\left.\mathrm{CD} 62 \mathrm{~L}^{-}\right)$, and naïve $\left(\mathrm{CD} 45 \mathrm{RA}^{+}\right.$ $\mathrm{CD}_{62 \mathrm{~L}^{+}}$) for $\mathrm{CD} 4$ (Additional File 2, Figure S2A) and CD8 (Additional File 4: Figure S3B) T cells. PB CD4 T cells were identified within an initial lymphocyte gate based on forward-scatter and side-scatter properties and then as viable, single $\mathrm{CD}^{+}$lymphocytes (Additional File 2: Figure S2B). Memory PB CD4 T cells were identified as CD45RA- For phenotypic analysis of LP CD4 and CD8 $\mathrm{T}$ cells, gates were established on isotype control staining for CD45RA, CD62L, Bcl-2, Ki67, CD38, Lag-3 and CTLA-4, Fluorescence minus one (FMO) for CD25 or FM4 for CD57, HLA-DR and PD-1. For PB CD4 T cells, isotype controls were used to determine specific staining for CD45RA, Bcl-2, Ki67, CD38, HLA-DR, CTLA-4, PD-1, Lag-3, Tim-3 and FMO for CD25 and CD57.

\section{Statistical analyses and graphing}

Statistical analyses and graphing were performed on GraphPad Prism for Windows (v8.4.1, GraphPad Software, La Jolla, CA). Unpaired $\mathrm{t}$-tests were performed to determine statistical differences between the age groups. Paired t-tests were performed to determine differences between donor-matched LP CD4 and CD8 T cells. Sample sizes $(\mathrm{N})$, means and standard error of the mean (SEM) are displayed in the figure legends. Outliers were identified using the Rout Method and removed from the analyses.

\section{Supplementary Information}

The online version contains supplementary material available at https://doi. org/10.1186/s12979-021-00217-0.

Additional file 1: Figure S1. Multi-color flow cytometry profiles to enumerate frequencies and phenotypic profiles of human colon LP CD4 T cells

Additional file 2: Figure S2. LP and PB memory CD4 T cell profiles. Additional file 3: Figure S3. Multi-color flow cytometry profiles to enumerate frequencies and phenotypic profiles of human colon LP CD8 T cells.

Additional file 4: Table S1. Frequencies and expression of survival, activation and immune-regulatory markers by LP CD8 T cells or LP CD4 T cells in younger persons.

Additional file 5: Table S2. Patient details for procured colonic tissue samples.

Additional file 6: Table S3. Antibodies and dyes used for multi-color flow cytometry.

\section{Abbreviations}

LP: Lamina propria; LPMC: Lamina propria mononuclear cells; PB: Peripheral blood; PBMC: Peripheral blood mononuclear cells; GMFI: Geometric mean 
fluorescence intensity; Gl: Gastrointestinal; EM: Effector memory; CM: Central memory; TDEM: Terminally differentiated effector memory

\section{Acknowledgements}

We gratefully acknowledge the study donors who provided blood samples and those who agreed to the use of discarded colonic tissue for research purposes. We acknowledge and thank other members of the Wilson laboratory for technical assistance with the processing of the tissue and blood specimens.

\section{Authors' contributions}

SMD and CCW designed the study. SMD, TAT, and AMC performed experiments and analyzed data. MDM provided access to surgical tissue. SMD and CCW wrote the primary version of the manuscript and are responsible for the final content. All authors read and approved the final manuscript.

\section{Funding}

This work was supported by the National Institute of Aging Grant R21AG062932 to C.W. The funding agency had no role in the design of the study, collection of samples or analysis and interpretation of the data nor in the writing of the manuscript.

\section{Availability of data and materials}

The datasets used and/or analyzed during the current study are available from the corresponding author on reasonable request.

\section{Ethics approval and consent to participate}

Two types of human specimens were used in this study: (a) colonic tissue samples obtained from discarded surgical tissue and (b) archived frozen PBMC.

Colonic tissue samples: Patients gave informed consent to allow unrestricted use of tissue specimens in research and all samples were de-identified to laboratory staff with only age, sex, the reason for surgery and relevant treatment status information available. The use of these samples for research purposes was reviewed by the Colorado Multiple Institutional Review Board (COMIRB) at the University of Colorado Anschutz Medical Campus and met criteria defined by their policies formed in accordance with regulations outlined by the FDA and OHRP, to be deemed "Not Human Research". (Protocols 07-0493 and 17-1746).

PBMC samples: All donors voluntarily gave written, informed consent. This study was approved by the COMIRB at the Anschutz Medical Campus.

(Protocols 98-496 and 11-1644).

\section{Consent for publication}

Not applicable.

\section{Competing interests}

The authors declare that they have no competing interests.

\section{Author details}

'Department of Medicine, University of Colorado Anschutz Medical Campus, Aurora, Colorado 80045, USA. 'Department of Surgery, University of Colorado Anschutz Medical Campus, Aurora, Colorado 80045, USA.

Received: 4 November 2020 Accepted: 2 February 2021 Published online: 13 February 2021

\section{References}

1. Franceschi C, Bonafe M, Valensin S, Olivieri F, De Luca M, Ottaviani E, De Benedictis $\mathrm{G}$. Inflamm-aging. An evolutionary perspective on immunosenescence. Ann N Y Acad Sci. 2000:908:244-54.

2. Fulop T, Larbi A, Dupuis G, Le Page A, Frost EH, Cohen AA, Witkowski JM, Franceschi C. Immunosenescence and Inflamm-aging as two sides of the same coin: friends or foes? Front Immunol. 2017:8:1960

3. Clark RI, Salazar A, Yamada R, Fitz-Gibbon S, Morselli M, Alcaraz J, Rana A, Rera M, Pellegrini M, Ja WW, et al. Distinct shifts in microbiota composition during Drosophila aging impair intestinal function and drive mortality. Cell Rep. 2015;12:1656-67.
4. Rera M, Clark Rl, Walker DW. Intestinal barrier dysfunction links metabolic and inflammatory markers of aging to death in Drosophila. Proc Natl Acad Sci U S A. 2012;109:21528-33.

5. Fransen F, van Beek AA, Borghuis T, Aidy SE, Hugenholtz F, van der Gaastde Jongh C, Savelkoul HFJ, De Jonge MI, Boekschoten MV, Smidt H, et al. Aged gut microbiota contributes to Systemical Inflammaging after transfer to germ-free mice. Front Immunol. 2017;8:1385.

6. Thevaranjan N, Puchta A, Schulz C, Naidoo A, Szamosi JC, Verschoor CP Loukov D, Schenck LP, Jury J, Foley KP, et al. Age-associated microbial Dysbiosis promotes intestinal permeability, systemic inflammation, and macrophage dysfunction. Cell Host Microbe. 2017;21:455-66 e454.

7. Mitchell EL, Davis AT, Brass K, Dendinger M, Barner R, Gharaibeh R, Fodor AA, Kavanagh K. Reduced intestinal motility, mucosal barrier function, and inflammation in aged monkeys. J Nutr Health Aging. 2017;21:354-61.

8. Walker EM, Slisarenko N, Gerrets GL, Kissinger PJ, Didier ES, Kuroda MJ Veazey RS, Jazwinski SM, Rout N. Inflammaging phenotype in rhesus macaques is associated with a decline in epithelial barrier-protective functions and increased pro-inflammatory function in CD161-expressing cells. Geroscience. 2019:41:739-57.

9. Wilson QN, Wells M, Davis AT, Sherrill C, Tsilimigras MCB, Jones RB, Fodor AA, Kavanagh K. Greater microbial translocation and vulnerability to metabolic disease in healthy aged female monkeys. Sci Rep. 2018;8:11373.

10. Steele AK, Lee EJ, Vestal B, Hecht D, Dong Z, Rapaport E, Koeppe J, Campbell TB, Wilson CC. Contribution of intestinal barrier damage, microbial translocation and HIV-1 infection status to an inflammaging signature. PLoS One. 2014;9:e97171.

11. Ma H, Tao W, Zhu S. T lymphocytes in the intestinal mucosa: defense and tolerance. Cell Mol Immunol. 2019;16:216-24.

12. Sorini C, Cardoso RF, Gagliani N, Villablanca EJ. Commensal Bacteria-specific CD4(+) T cell responses in health and disease. Front Immunol. 2018:9:2667.

13. Dillon SM, Wilson CC. What is the collective effect of aging and HIV on the gut microbiome? Curr Opin HIV AIDS. 2020;15:94-100.

14. Kumar BV, Connors TJ, Farber DL. Human T cell development, localization, and function throughout life. Immunity. 2018:48:202-13.

15. Kumar BV, Ma W, Miron M, Granot T, Guyer RS, Carpenter DJ, Senda T, Sun X, Ho SH, Lerner H, et al. Human tissue-resident memory T cells are defined by Core transcriptional and functional signatures in lymphoid and mucosal sites. Cell Rep. 2017;20:2921-34.

16. Sathaliyawala T, Kubota M, Yudanin N, Turner D, Camp P, Thome Jر, Bickham KL, Lerner $\mathrm{H}$, Goldstein M, Sykes M, et al. Distribution and compartmentalization of human circulating and tissue-resident memory $T$ cell subsets. Immunity. 2013;38:187-97.

17. Thome JJ, Yudanin N, Ohmura Y, Kubota M, Grinshpun B, Sathaliyawala T, Kato T, Lerner H, Shen Y, Farber DL. Spatial map of human T cell compartmentalization and maintenance over decades of life. Cell. 2014;159: 814-28

18. Dillon SM, Liu J, Purba CM, Christians AJ, Kibbie JJ, Castleman MJ, MCCarter MD, Wilson CC. Age-related alterations in human gut CD4 T cell phenotype, T helper cell frequencies, and functional responses to enteric bacteria. J Leukoc Biol. 2020;107:119-32.

19. Senda T, Dogra P, Granot T, Furuhashi K, Snyder ME, Carpenter DJ, Szabo PA, Thapa P, Miron M, Farber DL. Microanatomical dissection of human intestinal T-cell immunity reveals site-specific changes in gut-associated lymphoid tissues over life. Mucosal Immunol. 2019;12:378-89.

20. Donaldson GP, Lee SM, Mazmanian SK. Gut biogeography of the bacterial microbiota. Nat Rev Microbiol. 2016;14:20-32.

21. Mowat AM, Agace WW. Regional specialization within the intestinal immune system. Nat Rev Immunol. 2014;14:667-85.

22. Goronzy JJ, Weyand CM. Successful and maladaptive T cell aging. Immunity, 2017:46:364-78.

23. Gustafson CE, Kim C, Weyand CM, Goronzy JJ. Influence of immune aging on vaccine responses. J Allergy Clin Immunol. 2020;145:1309-21.

24. Pangrazzi L, Weinberger B. T cells, aging and senescence. Exp Gerontol. 2020;134:110887.

25. Szabo PA, Miron M, Farber DL. Location, location, location: tissue resident memory T cells in mice and humans. Sci Immunol. 2019:4:eaas9673.

26. Heigele A, Joas S, Regensburger K, Kirchhoff F. Increased susceptibility of CD4+ T cells from elderly individuals to HIV-1 infection and apoptosis is associated with reduced CD4 and enhanced CXCR4 and FAS surface expression levels. Retrovirology. 2015;12:86. 
27. Leng Q, Bentwich Z, Borkow G. CTLA-4 upregulation during aging. Mech Ageing Dev. 2002;123:1419-21.

28. Vukmanovic-Stejic M, Sandhu D, Seidel JA, Patel N, Sobande TO, Agius E, Jackson SE, Fuentes-Duculan J, Suarez-Farinas M, Mabbott NA, et al. The characterization of varicella zoster virus-specific T cells in skin and blood during aging. J Invest Dermatol. 2015;135:1752-62.

29. Reitsema RD, Hid Cadena R, Nijhof SH, Abdulahad WH, Huitema MG, Paap $\mathrm{D}$, Brouwer $\mathrm{E}$, Boots AMH, Heeringa P. Effect of age and sex on immune checkpoint expression and kinetics in human T cells. Immun Ageing. 2020; 17:32.

30. Canaday DH, Parker KE, Aung H, Chen HE, Nunez-Medina D, Burant CJ. Agedependent changes in the expression of regulatory cell surface ligands in activated human T-cells. BMC Immunol. 2013;14:45.

31. Czesnikiewicz-Guzik M, Lee WW, Cui D, Hiruma Y, Lamar DL, Yang ZZ, Ouslander JG, Weyand CM, Goronzy JJ. T cell subset-specific susceptibility to aging. Clin Immunol. 2008;127:107-18.

32. Lages CS, Suffia I, Velilla PA, Huang B, Warshaw G, Hildeman DA, Belkaid Y, Chougnet $C$. Functional regulatory $T$ cells accumulate in aged hosts and promote chronic infectious disease reactivation. J Immunol. 2008;181:183548.

33. van den Brom RRH, van der Geest KSM, Brouwer E, Hospers GAP, Boots AMH. Enhanced expression of PD-1 and other activation markers by CD4+ T cells of young but not old patients with metastatic melanoma. Cancer Immunol Immunother. 2018;67:925-33.

34. Yukl SA, Shergill AK, Girling V, Li Q, Killian M, Epling L, Li P, Kaiser P, Haase A, Havlir DV, et al. Site-specific differences in T cell frequencies and phenotypes in the blood and gut of HIV-uninfected and ART-treated HIV+ adults. PLoS One. 2015;10:e0121290.

35. De Velasco G, Je Y, Bosse D, Awad MM, Ott PA, Moreira RB, Schutz F, Bellmunt J, Sonpavde GP, Hodi FS, et al. Comprehensive meta-analysis of key immune-related adverse events from CTLA-4 and PD-1/PD-L1 inhibitors in Cancer patients. Cancer Immunol Res. 2017:5:312-8.

36. Joosse ME, Nederlof I, Walker LSK, Samsom JN. Tipping the balance: inhibitory checkpoints in intestinal homeostasis. Mucosal Immunol. 2019:12. $21-35$.

37. Hosseini A, Gharibi T, Marofi F, Babaloo Z, Baradaran B. CTLA-4: from mechanism to autoimmune therapy. Int Immunopharmacol. 2020;80: 106221.

38. Sharpe AH, Pauken KE. The diverse functions of the PD1 inhibitory pathway. Nat Rev Immunol. 2018;18:153-67.

39. Cicala C, Arthos J, Fauci AS. Role of T-cell trafficking in the pathogenesis of HIV disease. Curr Opin HIV AIDS. 2019;14:115-20.

40. Zundler S, Neurath MF. Immunopathogenesis of inflammatory bowel diseases: functional role of T cells and T cell homing. Clin Exp Rheumatol. 2015;33:S19-28

41. Luu M, Weigand K, Wedi F, Breidenbend C, Leister H, Pautz S, Adhikary T, Visekruna A. Regulation of the effector function of CD8(+) T cells by gut microbiota-derived metabolite butyrate. Sci Rep. 2018;8 14430.

42. Tanoue T, Morita S, Plichta DR, Skelly AN, Suda W, Sugiura Y, Narushima S, Vlamakis $\mathrm{H}$, Motoo I, Sugita K, et al. A defined commensal consortium elicits CD8 T cells and anti-cancer immunity. Nature. 2019;565:600-5.

43. Dillon SM, Guo K, Castleman MJ, Santiago ML, Wilson CC. Quantifying HIV-1mediated gut CD4+ T cell death in the Lamina Propria aggregate culture (LPAC) model. Bio-protocol. 2020;10:e3486

44. Dillon SM, Lee EJ, Donovan AM, Guo K, Harper MS, Frank DN, McCarter MD, Santiago ML, Wilson CC. Enhancement of HIV-1 infection and intestinal CD4+ T cell depletion ex vivo by gut microbes altered during chronic HIV-1 infection. Retrovirology. 2016;13:5.

45. Dillon SM, Manuzak JA, Leone AK, Lee EJ, Rogers LM, McCarter MD, Wilson CC. HIV-1 infection of human intestinal lamina propria CD4+ T cells in vitro is enhanced by exposure to commensal Escherichia coli. J Immunol. 2012; 189:885-96

46. Dillon SM, Rogers LM, Howe R, Hostetler LA, Buhrman J, McCarter MD, Wilson CC. Human intestinal lamina propria CD1c+ dendritic cells display an activated phenotype at steady state and produce IL-23 in response to TLR7/ 8 stimulation. J Immunol. 2010;184:6612-21.

47. Howe R, Dillon S, Rogers L, McCarter M, Kelly C, Gonzalez R, Madinger N, Wilson CC. Evidence for dendritic cell-dependent CD4(+) T helper-1 type responses to commensal bacteria in normal human intestinal lamina propria. Clin Immunol. 2009;131:317-32.
48. Dillon SM, Friedlander LJ, Rogers LM, Meditz AL, Folkvord JM, Connick E, McCarter MD, Wilson CC. Blood myeloid dendritic cells from HIV-1-infected individuals display a proapoptotic profile characterized by decreased BCl-2 levels and by caspase-3+ frequencies that are associated with levels of plasma viremia and T cell activation in an exploratory study. J Virol. 2011;85: 397-409.

49. Dillon SM, Lee EJ, Bramante JM, Barker E, Wilson CC. The natural killer cell interferon-gamma response to bacteria is diminished in untreated HIV-1 infection and defects persist despite viral suppression. J Acquir Immune Defic Syndr. 2014;65:259-67.

50. Dillon SM, Robertson KB, Pan SC, Mawhinney S, Meditz AL, Folkvord JM, Connick E, McCarter MD, Wilson CC. Plasmacytoid and myeloid dendritic cells with a partial activation phenotype accumulate in lymphoid tissue during asymptomatic chronic HIV-1 infection. J Acquir Immune Defic Syndr. 2008;48:1-12.

\section{Publisher's Note}

Springer Nature remains neutral with regard to jurisdictional claims in published maps and institutional affiliations.

Ready to submit your research? Choose BMC and benefit from:

- fast, convenient online submission

- thorough peer review by experienced researchers in your field

- rapid publication on acceptance

- support for research data, including large and complex data types

- gold Open Access which fosters wider collaboration and increased citations

- maximum visibility for your research: over $100 \mathrm{M}$ website views per year

At $\mathrm{BMC}$, research is always in progress.

Learn more biomedcentral.com/submissions 